\title{
LA INTERPRETACIÓN ESTÉTICA DE LA VERDAD DIÁLOGO ENTRE APOLO Y DIONISIO
}

\section{ARturo Berumen CAMPOS ${ }^{1}$ Y JACqueline ORTIZ AndRADE ${ }^{2}$}

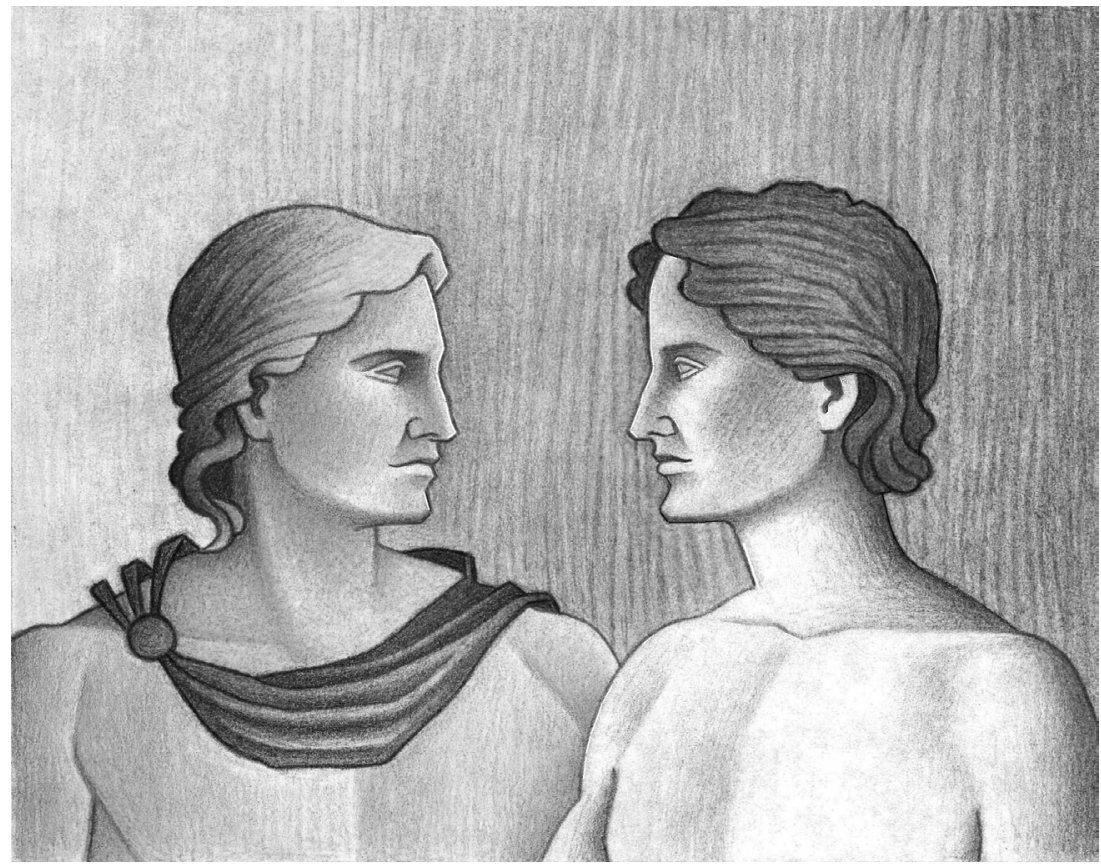

Apolo y Dionisio, dibujo de Manuel Berumen Campos

1 Universidad Autónoma Metropolitana, Unidad Azcapotzalco. Sistema Nacional de Investigadores, nivel I.

2 Profesora de Filosofía del derecho en la Facultad de Derecho de la UNAM. 
Apolo.- ¿ ¿Por qué siempre que dices algo de ética o de filosofía, tienes que mencionar el nombre del filósofo que lo dijo? En la ciencia, nunca o casi nunca hacemos eso. Simplemente formulamos y ponemos a prueba los enunciados científicos.

Dionisio. - Es que la filosofía no es una ciencia, sino un arte.

Apolo.- ¿ ¿No es una ciencia? Entonces no vale nada, racionalmente.

Dionisio. - No bueno, sí es una ciencia, pero es una ciencia distinta.

Apolo.--Más bien yo creo que es o fue, una "protociencia", un primer intento de hacer ciencia, pero ahora ya no es necesaria, me parece muy arcaica.

Dionisio. - No sabes lo que dices querido "cientificista". Sin la filosofía, la ciencia no sería nada.

Apolo.-La filosofía, querido "esteticista", no hace sino repetir lo que la ciencia ya ha dicho y ha descubierto, no descubre nada nuevo.

Dionisio. - Justamente al revés, adorador de la ciencia. La ciencia ha utilizado siempre los conceptos y las formas de razonamiento que ha elaborado la filosofía y que ha puesto a su servicio.

Apolo.- Necesito que me des pruebas al respecto, si no quedarás como un charlatán estimado "esteticista".

Dionisio. - Bien, te voy a dar sólo tres casos, para que seas más humilde, hijo de Newton. En primer lugar, el concepto de verdad. Me puedes decir, ¿qué es la verdad?

Apolo.- ¿La verdad científica?

Dionisio.- Sí claro, la verdad científica

Apolo.-Bueno, cuando una teoría o un experimento son comprobados empíricamente.

Dionisio.-Entonces, ¿dónde está la verdad? 
Apolo.- ¿Ciómo dónde? Ya vas a empezar con tus abstracciones.

Dionisio.- Sí ¿en qué parte del mundo está la verdad?

Apolo.- - La verdad, no te entiendo.

Dionisıo. - Mira, ahorita mismo que dijiste "verdad", ¿dónde está la verdad?

Apolo.- ¿YYo dije verdad?

Dionisio. - Sí, y lo acabas de decir otra vez. Entonces, ¿dónde está la verdad?

Apolo.- No seas necio, y dime lo que quieres decir.

Dionisio.- Si dices "la verdad", la verdad está en tu decir, en tu hablar, en tu lenguaje.

Apolo. - Ya ves, la filosofía son puras simplezas. La palabra "verdad", pues sí, es lenguaje ¡Qué obviedad! Pero el concepto de verdad es otra cosa.

Dionisio.-Bien, donde está el concepto de verdad.

Apolo.- ¿Ciómo que dónde? Pues en la mente ¿dónde más?

Dionisio.- ¿ ¿En la mente? Entonces no es un concepto científico, pues lo científico tiene que ser empírico, comprobable, ¿no es así?

Apolo.-Bueno sí, pero...

Dionisio. - ¿Se puede demostrar la existencia de la mente?

Apolo.-Bueno, está bien, no está en la mente. Entonces, la verdad está en las cosas empíricas. Por ejemplo, si digo la causa del SIDA es el VIH (virus de la inmunodeficiencia humana), se puede demostrar que sí es verdad, experimentalmente.

Dionisio.- ¿¿Quieres decir que la verdad está en el virus?

Apolo.- - La verdad de que es la causa del SIDA, sí.

Dionisio. - La verdad no puede estar en las cosas del mundo. Las cosas son, eso es todo. 
Apolo.- ¿ ¿Entonces dónde está la verdad?

Dionisio.- - La verdad está en los enunciados o no está.

Apolo.- ¿Ciómo crees?

Dionisio. - Claro que sí, ¿no dijiste que era verdad el enunciado de que "la causa del SIDA es el VIH"? Lo que es verdadero o no es verdadero es el enunciado, no el virus.

Apolo.- Sí, pero el enunciado es verdadero si el VIH es la verdadera causa del SIDA, si no, no. Por tanto, la verdad del enunciado está en el virus.

Dionisio. - Más bien sabemos que el enunciado es verdadero si se corresponde con los hechos, y no lo es si no se corresponde con ellos.

Apolo.- Pues eso es lo que te dije desde un principio.

Dionisio. - Fue lo que intentaste decir y no pudiste, porque no has leído a Aristóteles, a Santo Tomás de Aquino ni a Tarski.

Apolo.- - Ya empezaste otra ve, con tu retahíla de nombres de autores.

Dionisio. - Para que los leas y te des cuenta de qué es lo que haces. Trabajas con un concepto de verdad, pero no sabes que es.

Apolo.- Para que veas, puedo hacerlo sin saber quées. ¿Para qué necesito a la filosofía?

Dionisio.-Ahora, ¿quién es el necio? Pues para que sepas lo que haces. Y eso es la filosofía. la reflexión sobre nuestras prácticas, como decía Wittgenstein. Perdón, te molestan los autores.

Apolo.- Pero no acabo de convencerme para que me sirve saber que es la verdad si yo sé encontrarla en la práctica.

Dionisio. - Pues para saber si lo estás haciendo bien, para mejorar y también para saber limitarte. ¿Hasta donde puedes aplicar el concepto científico de verdad?

Apolo.- ¿Qué? ¿Hay otros conceptos de verdad? 
Dionisio.- - Así es. La verdad científica se entiende como "la correspondencia de los enunciados con los hechos" de acuerdo con...

Apolo.- - Ya, ya, no me interesa saber quien.

Dionisio. - Entonces ¿Cómo vas a profundizar en este concepto de verdad, si no sabes quién es el autor?

Apolo.- No me interesa profundizar. Mejor dime qué otro concepto de verdad conoces.

Dionisio.-Bueno, está el concepto de "verdad como coherencia".

Apolo.- ¿Qué, no es lo mismo?

Dionisio. - No, querido cientificista. En la verdad como correspondencia, se corresponden o no se corresponden los enunciados con los hechos, en cambio, en la verdad como coherencia, lo enunciados son o no son coherentes con otros enunciados. ¿Ves la diferencia?

Apolo.- - La verdad no. Ponme un ejemplo.

Dionisio.- Por ejemplo, si digo "El salario de los maestros de la UNAM es justo", ese enunciado ¿es verdadero o es falso?

Apolo.-Depende, algunos maestros ganan bien y otros no.

Dionisio. - Pero el enunciado no es si ganan bien o no, sino si ganan lo justo.

Apolo.-Entonces debes definir el concepto de justicia.

Dionisio.- ;Claro! Pero eso lo hace la filosofía.

Apolo.- ¿Y bien?

Dionisio. - Aquí viene el problema de los autores clásicos. Podemos definir la justicia con Aristóteles, con Marx, con Rawls, entre otros.

Apolo.- ¿ ¿También existen tres conceptos de justicia?

Dionisio.- - Guando menos. De hecho existen muchos más. 
Apolo.- ¿Muchos más? Entonces la ética no es una ciencia. Nosotros los científicos sólo tenemos una definición para cada cosa.

Dionisio.-Bueno, ¿quién sabe? Pero ese es justamente el problema de los autores. Como hay muchas concepciones de los problemas filosóficos, tenemos que distinguirlas por corrientes y por autores, para saber de cuál de ellas estamos hablando.

Apolo.- ¿YY cuál es la verdadera?

Dionisio. - Ese el problema de la verdad como coherencia. Que sólo es probable.

Apolo.--Pero ya dime que es, la dichosa verdad como coherencia.

Dionisio. - Espérate, mejor te doy un concepto de justicia para después llegar al de verdad.

Apolo.-Está bien, ¿qué otro?

Dionisio.- Según Aristóteles (te darás cuenta que es inevitable citar a nuestros clásicos de ética filosófica), la justicia es darle a cada quien en proporción a sus méritos o a sus culpas, según se trate de premios o castigos, respectivamente.

Apolo.--Pero puede suceder que los que ganan más lo merecen y quienes ganan menos, merecen menos. ¿No es así?

Dionisio. - Claro, pero también puede suceder que los que ganan más sean los favoritos de los príncipes y lo que ganan menos sean sus críticos y eso nada tiene que ver con los méritos.

Apolo.--Entonces, ¿cómo saber la verdad de tu enunciado, si no investigamos si corresponde con los hechos?

Dıonisıo. - No tan rápido, mi estimado cientificista. Primero, hay que definir lo que se entiende por méritos, no es algo obvio. Y después debemos determinar como medirlo. Ese es el problema más grande para saber si algo es justo. Pues todo mundo siente que tiene más méritos que otro y si no es tratado como espera se considera tratado injustamente. 
Apolo.-Entonces, estimado esteticista tienes que comparar tu definición de justicia, con tu definición de méritos...

Dionisio. - Es decir, buscas la coherencia de dos enunciados, lo cual es la verdad como coherencia que buscábamos.

Apolo.-Pero, Dionisio, al final tienes que apelar a los hechos, para ver si hay o no hay correspondencia de dichos enunciados con los hechos, para saber si los maestros son tratados justamente de acuerdo con sus méritos o no lo son.

Dionisio. - El problema en ética y también en derecho es que los hechos ya pasaron, sólo queda el registro de los mismo, como pueden ser, en nuestro ejemplo, las nóminas, los cheques, los depósitos que no son hechos, sino enunciados.

Apolo.- Ay, no juegues. Son hechos, ¿cómo enunciados?

Dionisio. - Enunciados protocolares, así les llaman los filósofos positivistas.

Apolo.- En ese caso, también la ciencia opera así.

Dionisio. - Es posible, pero la investigación ética y jurídica busca la coherencia de una buena cantidad de enunciados generales y particulares.

Apolo.- Te decía, la ciencia también procede así. Busca la coherencia de las teorías, de las variables, de los indicadores, de los resultados, de la discusión con otros investigadores. No veo dónde está la diferencia entre la ética y la ciencia.

Dionisio.-Antes de continuar, ¿estarás de acuerdo en que ya la discusión filosófica nos ha ayudado a esclarecer, aunque sea un poco, cómo hacemos nuestras prácticas?

Apolo.-Bueno sí tengo que reconocer que me ha ayudado a entender algunas de mis propias prácticas. Pero ¿existe otro concepto de verdad? Me dijiste que ibas a referirte a tres, ¿cuál es el otro? 
Dionisio. - Hay dos más. La verdad como consenso y la verdad como develamiento. La verdad como consenso, se refiere a un consenso ideal, no real.

Apolo.- ¿ ¿Otra vez con tus idealismos metafísicos?

Dionisio.-Cállate, ni sabes que es metafísica.

Apolo.-Está bien, continúa.

Dionisio. - Bueno, te decía que es un consenso ideal, no real.

Apolo.-Espérame. ¿Quieres decir que si todos están de acuerdo en algo, entonces será verdad?

Dionisio.- Claro que no, ¿qué no estás escuchando? Te dije consenso ideal, jideal! No real, ¡no real!

Apolo.- Perdón, si no es real ¿cómo es entonces?

Dionisio. - Pues déjame hablar, no me interrumpas. Ideal significa, que la verdad de un enunciado se argumenta por alguien ante alguien y que hay que argumentar de tal modo que sea capaz de convencerse incluso al que no está de acuerdo. No que se convenza, si no que sea capaz de convencerlo.

Apolo.- ¿Cómo? No entiendo, ¿qué lo convenza o que no lo convenza?

Dionisio. - No, que se argumente de manera tal que sea capaz de convencer al que no esté de acuerdo. Es decir, argumentar desde el punto de vista del otro, no de uno mismo. O como dice Habermas (perdón por citar a mis clásicos), hay que argumentar en actitud hipotética, en actitud objetivamente, en actitud de tercera persona.

Apolo.--Pero si el enunciado es verdadero, aunque no convenzas al otro.

Dionisio. - Ese es el problema de los cientificistas. Green que si el enunciado es verdadero para ellos, lo es para todo el mundo.

Apolo.- ;Claro que no creemos eso! Por eso, nosotros publicamos nuestros trabajos, para discutirlos con los demás científicos. 
Dionisio.- ¡Pero no con los que no son científicos!

Apolo.-Algunas veces sí. Pero eso ya no es parte de la investigación científica, sino de divulgación científica.

Dionisio. - Pero es una condición o una consecuencia de la ciencia. ¿O no es así?

Apolo.- Si, pero no es parte de la ciencia.

Dionisio. - Está bien. Pero lo que quiero hacer destacar es que en una discusión técnica o en una discusión científica hay que tomar en cuenta a tu auditorio. Tienes el deber ético de asumir, idealmente, el punto de vista de tu colega, de quien apoya tus proyectos y de quien sufre las consecuencias.

Apolo.- ¿ ¿Deber ético?

Dionisio.- Sí, porque la verdad como consenso, está en el diálogo.

APolo. - ¿La verdad o la ética?

Dionisio.- - Las dos.

Apolo.- ¿Por qué?

Dionisio. - Porque argumentas de distinta manera ante tus colegas que ante el público en general.

Apolo.- - Sí, pero el contenido es el mismo en ambos casos, sólo cambia la forma de expresión.

Dionisio. - Pero lo que te contestan, ¿no te hacen cambiar el contenido de tu "verdad"?

Apolo.- Con los colegas, por supuesto, para eso discute uno, para poner a prueba los descubrimientos. Pero con el público en general, lo dudo.

Dionisio.-Entonces, cuando menos dentro de la comunidad científica, aceptas que la verdad no sólo está en los enunciados, sino también en el diálogo o en la discusión. 
Apolo.--Más bien, del diálogo proviene la verdad. Eso sí. Pero del diálogo con los colegas, no con el público.

Dionisio. - Con eso me basta. No basta sólo tu punto de vista, o sea, una actitud asertórica, o una actitud participante, o una actitud de primera o segunda persona, para lograr la verdad, sino que es necesario un consenso, racionalmente motivado.

Apolo.- - Si, en eso sí estoy de acuerdo.

Dionisio. - ¿Y estarás de acuerdo que también ahí reside la ética científica?

Apolo.- ¿ ¿En dónde?

Dionisio.- En el diálogo.

Apolo.- ¿ ¿Por qué?

Dionisio.- Porque es un deber ético escuchar al otro, aceptar cuando uno está equivocado, reconocer los méritos del otro, etcétera.

Apolo.-Sí, el científico debe ser humilde.

Dionisio.- ¿Como Sócrates?

APolo.- Sí, como Sócrates.

Dionisio. - Y ¿no crees que también debería ser así con los que no pertenecen al gremio científico, con los profanos?

Apolo.-Bueno, ahí no estoy tan seguro.

Dionisio. - Pero estarás de acuerdo que los que van a ser afectados, para bien o para mal, por los descubrimiento científicos, deben poder se escuchados por los científicos.

Apolo.- Quizás en las condiciones y en las consecuencias de la aplicación de la ciencia, pero en el proceso científico en sí, no me parece.

Dionisio. - Digamos que la ética está tanto en el diálogo interno como en el externo, y la verdad sólo en el interno a la ciencia.

Apolo.-Podría aceptarlo. 
Dionisio. - Es decir, desde ambos puntos de vista, el científico, como cualquiera que entabla un diálogo, tiene que saber asumir actitudes hipotéticas y no sólo asertóricas, aunque se trate de personas que no son expertas en el tema.

Apolo.- ${ }_{\mathrm{C} P e r o}$ eso quiere decir que no tengo derecho a afirmar o a negar, categóricamente mis ideas, mis descubrimientos, mis teorías, en fin, mi verdad?

Dionisio.-Es decir, ¿si tienes derecho a ser dogmático e impositivo? No, no tienes derecho a ser intolerante.

Apolo.- ¿Yo dogmático? ¿Yo intolerante?

Dionisio. - Pues sí, tú y todos los cientificistas como tú, que han hecho de la ciencia un nuevo dogma, un nueva religión, que no admite la duda, menos la crítica.

Apolo.- Si fuera así, no estaría aquí soportando tus especulaciones y tus impertinencias.

Dionisio.- A eso me refiero. El científico cree que es una molestia tomar en serio las dudas y las críticas de los demás, en especial de los filósofos. Pero no se da cuenta que discutir bajo supuestos, en actitud hipotética en eso consiste, no tan sólo el desarrollo de la verdad, sino a ética científica. La ética, Apolo cientificista, no es un añadido a la ciencia, es un elemento necesario para el desarrollo de la verdad científica. No es una condición que gratuitamente nos hacen a los filósofos, sino un favor que se hacen a sí mismos.

Apolo.--Estoy de acuerdo, pero los científicos no son así, no serían verdaderos científicos.

Dionisio. - Tienes razón, no son científicos, sino cientificistas, como los llama Habermas.

Apolo.- ¿Y cuál es el otro tipo de verdad que mencionabas?

Dionisio. - La más importante de todas y que comprende a las demás. La verdad como develamiento: "Aletheia" en griego. Es descorrer el velo que nos oculta la realidad. 
Apolo.- Esa es la verdad científica.

Dionisio. - Es todas ellas: descorre el velo de la ignorancia y brilla la verdad científica; descorre el velo de los prejuicios, y nos ilumina la verdad hermenéutica; descorre el velo de la ideología y se nos revela la verdad de la ética.

Apolo.- ¿Y cómo hace todo eso la Aletheia? ¿Con la ciencia?

Dionisio. - No exactamente.

Apolo.- ¿ ¿No me digas que es con la ética?

Dionisio. - Tampoco.

Apolo.- ¿Entonces?

Dionisio. - Es con lo que menos te imaginas, querido Apolo. Con el arte, con la poesía. La poesía es "la desocultación del ente". "El como poner-en-obra-la-verdad es Poesía", nos dice Heidegger (perdón, cité de nuevo).

Apolo.--Ahí, sí ya no estoy de acuerdo, nuevamente. Me parece que esta discusión ya la hemos tenido desde hace mucho tiempo. Te puedo aceptar que la ciencia guarda algunas relaciones con la ética, pero ¿con la estética? No, es eso ya demasiado ¿Me quieres explicar qué tiene que ver la poesía con la ciencia?

Dionisio. - Discutíamos estas cosas desde que éramos jóvenes, y desde entonces estábamos en desacuerdo.

Apolo.- Sí, recuerdo que yo prefería las matemáticas y tu la literatura. Pero no recuerdo que confundieras una con la otra, como pareces hacerlo ahora.

Dionisio. - No es que los confunda, sino que, de acuerdo con Gadamer (ya aceptaste que es necesario citar a los autores en filosofía, ¿no?) el arte y, en especial, la poesía, no sólo tienen un función de producir placer estético, sino una función epistemológica, es decir, ayudan a producir nuevo conocimiento.

Apolo.- ¿Cómo? No alcanzo a comprenderlo. 
Dionisio. - Por ejemplo, veamos la metáfora, que es un elemento esencial de la poesía. Las metáforas derivan de la analogía, la que nos permite conocer lo desconocido a partir de lo conocido en virtud de una semejanza de relación entre el tema y el foro. Por ejemplo, sea la siguiente analogía: la nulidad es al contrato como la muerte es a la vida. De la cual derivan las siguientes metáforas: la nulidad es la muerte del contrato y la muerte es la nulidad de la vida. Las cuales son bellas y verdaderas a la vez. Más aún son verdaderas porque son bellas. De ahí derivo yo una propuesta: la validez de una analogía deriva de la belleza de sus metáforas. ¿Cómo la ves, estimado Apolo?

Apolo.-Bueno tal vez, pueda ser válido para la verdad ética o la verdad jurídica, pero, lo dudo para la verdad científica. Ponme un ejemplo de verdad científica.

Dionisio.- No, lo vas a poner tú.

APOLO.- ¿ ¿Yo?

Dionisio. - Sí. Dime ¿cómo es la estructura del ADN? Para poner algo de tu campo de investigación.

Apolo.--Es una doble hélice, todo el mundo lo sabe.

Dionisio.- ¿A qué se parece?

Apolo.- A una escalera de caracol. Y ¿eso qué?

Dionisio. - Pues es una analogía. Y según tú me has contado, así lo descubrió el mismo Watson: viendo la escalera de caracol de su casa. ¿No es así?

Apolo.- - Si, así sucedió.

Dionisio. - Pues bien. Intentemos hacer una analogía y derivar sus metáforas. ¿Te parece?

Apolo.--Está bien, aunque no sé a donde nos conduce esto.

Dionisio.- ¿ ¿En que se parece el ADN y la escalera de caracol? 
Apolo.-Bueno en ambos tienen dos tiras enroscadas y peldaños que las unen.

Dionisio.- ¡Perfecto! Ya tenemos los elementos del tema y del foro. Ahora sólo busquemos los nombres adecuados. ¿Podemos decir que las tiras son las guías de las bases?

Apolo.- Sí, porque según el orden de la cadena es el orden de las bases.

Dionisio. - Y las bases son los peldaños de la escalera.

Apolo.-De acuerdo.

Dionisio. - Bueno ya tenemos la analogía: las cadenas de ADN son a las bases como las guías de la escalera de caracol son a los peldaños. Por lo tanto, tenemos las siguientes metáforas: las cadenas de ADN son las guías de las bases, y las guías de la escalera de caracol son las cadenas de los peldaños. ¿Cómo la ves?

Apolo.--Regular, solamente, aunque sí ilustra lo que pasa en el ADN.

Dionisio. - Habría que buscar otros nombres más precisos. Tal vez, buscando en la etimología: hélice significa en griego "caracol". El ADN es el caracol de la vida, o el caracol es la hélice de la vida, ¿no?

Apolo.- No importa ya. Ya entendí lo que quieres decir. ¿Que la ciencia es la poesía de la verdad?

Dionisio. - O al revés; la poesía es la ciencia de la belleza.

Apolo.- ¿'Y la ética?

Dionisio. - Bueno, la ética me parece que podría ser la estética de la verdad.

Apolo.- ¿ ¿La estética?

Dionisio. - Bueno, sería una buena conclusión de nuestro diálogo la estética como "Aletheia", es decir, como develamiento de la verdad de la ética y de la ciencia. ¿Cómo la vez Apolo? 
Apolo.- No está mal, como hipótesis a refutar, Dionisio.

Dionisio.-Empecemos de nuevo, pues.

Apolo.-Empecemos.

Dionisio. - Y terminamos. 